\title{
DETERMINAÇÃo DE ESPÉCIE INDICADORA E COMPARAÇÃo DE Genótipos de Girassol Quanto ao Potencial Alelopático ${ }^{1}$
}

\author{
Determination of Indicative Species and Comparison of Sunflower Genotypes as to their \\ Allelopathic Potential
}

\author{
SILVA, H.L. ${ }^{2}$, TREZZI. M.M. ${ }^{3}$, MARCHESE, J.A. ${ }^{3}$, BUZZELLO, G. ${ }^{2}$, MIOTTO Jr. E. ${ }^{4}$, PATEL, F. ${ }^{4}$, \\ DEBASTIANI, F. ${ }^{4}$ e FIORESE, J. ${ }^{4}$
}

\begin{abstract}
RESUMO - Na agricultura atual, o método mais utilizado para o controle de plantas daninhas é o químico, em razão da facilidade de uso, elevada eficiência e baixa necessidade de mão de obra. No entanto, a utilização inadequada desses produtos provoca problemas ao ambiente e à saúde humana. Cresce, portanto, a busca por métodos alternativos de controle de plantas daninhas, menos demandadores de energia e menos tóxicos e agressivos ao ambiente. Este trabalho objetivou avaliar o efeito alelopático da cultura do girassol (Helianthus annuus) sobre diferentes espécies de plantas daninhas e cultivadas, em dois experimentos realizados em delineamento experimental completamente casualizado, utilizando o método da semeadura em substituição. O primeiro experimento foi realizado com quatro repetições, em esquema bifatorial. O primeiro fator foi constituído por seis espécies indicadoras: picão-preto (Bidens pilosa), corda-de-viola (Ipomoea grandifolia), caruru (Amaranthus hybridus), alface (Lactuca sativa, cultivar Aurélia), tomate (Lycopersicon esculentum, cultivar Santa Cruz), trigo (Triticum aestivum, cultivar BRS 208); e o segundo, pela presença ou não de plântulas de girassol. O segundo experimento foi composto por 24 tratamentos, representados por 23 genótipos de girassol e por uma testemunha sem girassol, utilizando-se quatro repetições. A espécie indicadora foi apenas o picão-preto. Em ambos os experimentos, no final do período de sete dias de convivio, foram avaliados o número de sementes germinadas e o comprimento radicular e da parte aérea das espécies indicadoras. Não foram observadas diferenças entre as porcentagens de germinação de quaisquer das espécies indicadoras avaliadas, em função da presença ou não das plântulas de girassol. A presença de plântulas de girassol estimulou o crescimento radicular das plântulas de tomate e trigo e inibiu o crescimento da parte aérea de picãopreto, trigo e corda-de-viola. Houve grande variabilidade de potencial alelopático entre genótipos de girassol sobre a germinação e o crescimento radicular e da parte aérea de Bidens pilosa. Os resultados demonstram que a técnica da semeadura em substituição é adequada para detectar efeitos estimulativos ou inibitórios de girassol sobre espécies indicadoras e para discriminar genótipos de girassol quanto à habilidade em inibir ou estimular plântulas de Bidens pilosa.
\end{abstract}

Palavras-chave: alelopatia, semeadura de substituição, seleção de espécie indicadora, seleção de genótipos.

\begin{abstract}
In modern agriculture, the chemical method is the most used for weed control because it is highly efficient, easy to apply, and demands limited labor. However, the inadequate use of chemical products can lead to environmental and human health problems. Thus, there is a growing need to search for alternative weed control methods using substances which are less energy-demanding, less toxic and less aggressive to the environment. This work aimed to evaluate the allelopathic potential of sunflower(Helianthus annuus) culture on different weed and cultivated
\end{abstract}

Recebido para publicação em 12.11.2008 e na forma revisada em 13.11.2009

2 Engô-Agr ${ }^{\circ}$., Mestre, Programa de Pós-Graduação em Agronomia, Universidade Tecnológica Federal do Paraná - UTFPR, Campus Pato Branco; <hluissilva@gmail.com>; ${ }^{3}$ Engo-Agr ${ }^{\circ}$., Dr., Professor do Curso de Agronomia - UTFPR, Campus Pato Branco, Via do Conhecimento, Km 1, Caixa Postal 571, 85503-390 Pato Branco-PR, <trezzi@utfpr.edu.br>; ${ }^{4}$ Acadêmico do Curso de Agronomia - UTFPR, Campus Pato Branco.

Planta Daninha, Viçosa-MG, v. 27, n. 4, p. 655-663, 2009 
species, in two experiments conducted in a completely randomized design, using the relay seeding technique. The first experiment was carried out with four repetitions, in a bi-factorial scheme. The first factor was constituted by six indicative target species: beggarticks (Bidens spp.), common morninglory (Ipomoea grandifolia), pigweed (Amaranthus hybridus), lettuce (Lactuca sativa, cv. Aurélia), tomato (Solanum lycopersicum, cv. Santa Cruz), and wheat (Triticum aestivum, $c v$. BRS 208). The second factor was constituted by the presence or absence of sunflower seedlings. The relay seeding technique was applied. The second experiment was composed by 24 treatments including 23 sunflower genotypes and a control without sunflower, with four repetitions. The indicative species was only the beggarticks. In both experiments, at the end of seven coexistence days, number of germinated seeds, and root and aerial part length of the target species were evaluated. No difference was observed among the germination percentages of the indicative species evaluated in the presence or absence of the sunflower plants. The presence of the sunflower plants stimulated tomato and wheat root growth and inhibited the growth of the beggartick, wheat and common morninglory aerial parts. There was great variability of the potential allelopathic effect of the sunflower genotypes on germination and root and aerial part length of Bidens pilosa. The results show that the relay seeding technique is adapted to discriminate stimulating and inhibiting effects of sunflower among indicative species and to discriminate sunflower genotypes in their ability to inhibit or stimulate Bidens pilosa plants.

Keywords: allelopathy, relay seeding technique, indicative species selection, genotype selection.

\section{INTRODUÇÃO}

Muitas plantas produzem metabólitos secundários com função fisiológica aparentemente inferior à dos metabólitos primários, porém com função ecológica muito importante para as plantas (Erasmo, 2004). Estudos sobre interações alelopáticas podem contribuir na busca de aleloquímicos naturais produzidos por plantas e de derivados sintéticos que possam ser usados como herbicidas naturais com propriedades mais específicas e menos prejudiciais ao ambiente, atendendo assim às necessidades atuais e futuras da agricultura (Macias et al., 1998; Peres et al., 2004).

Vários métodos podem ser utilizados para caracterizar efeitos alelopáticos. Um dos mais empregados é a obtenção de extratos de partes das plantas com o uso de solventes, dos quais a água é um dos mais utilizados. O uso de extratos é uma ferramenta muito útil na identificação do potencial alelopático de espécies vegetais. A definição da composição do extrato dependerá do tipo de solvente ou da associação de solventes utilizada para sua obtenção e também do método de extração utilizado. Solventes polares, como a água, têm grande afinidade por compostos polares, enquanto solventes apolares, como o hexano, apresentam grande afinidade por substâncias apolares.
A semeadura em substituição é outro método que vem sendo utilizado na detecção e avaliação de efeitos alelopáticos, porém é pouco usada em pesquisas desenvolvidas no Brasil. Essa técnica foi utilizada por Olofsdotter et al. (1999) em experimento realizado com diferentes genótipos de arroz (Oryza sativa), em que foram identificados aqueles com potencial alelopático superior sobre a germinação e o desenvolvimento de plântulas de capim-arroz (Echinochloa crusgalli). Esse método utiliza, em um primeiro momento, a semeadura em laboratório da planta doadora, com suspeita de atividade alelopática, seguindo-se, alguns dias após, a semeadura de uma espécie indicadora, que irá se desenvolver juntamente com plântulas da espécie doadora. O convivio entre as espécies permite avaliar o efeito de substâncias liberadas pela espécie doadora.

A espécie indicadora utilizada para avaliar o potencial alelopático deve apresentar diversos atributos, entre os quais possuir alto indice de germinação em meio natural, disponibilidade de sementes, homogeneidade entre os indivíduos, além de alta sensibilidade à ação de diferentes compostos alelopáticos. A resistência ou tolerância aos metabólitos secundários que funcionam como aleloquímicos é mais ou menos específica, existindo espécies mais sensiveis que outras, como, por 
exemplo, a alface (Lactuca sativa) e o tomate (Lycopersicon esculentum) - por isso mesmo, muito usadas em biotestes de laboratório (Ferreira \& Áquila, 2000). A utilização de espécie daninha como indicadora pode representar problemas, como a desuniformidade de germinação, devido à baixa homogeneidade dos propágulos, diferentemente do que ocorre quando são utilizadas espécies cultivadas em escala comercial.

O girassol (Helianthus annuus) é uma espécie de grande interesse comercial, conhecida por apresentar elevada produção de compostos do metabolismo secundário (Macías et al., 2003). A importância da cultura do girassol em sistemas de rotação e sucessão de culturas no Brasil se deve à sua maior adaptação às temperaturas baixas e até mesmo a geadas nos estádios iniciais de desenvolvimento do que culturas tradicionalmente implantadas na primavera, como a soja e o milho. Também, o girassol possui relativa tolerância à deficiência hídrica (Castro \& Farias, 2005), que é o motivo de sua expansão de cultivo em Estados da região Centro-Oeste do Brasil, na última década. Além disso, por pertencer à família Asteraceae, o girassol não é hospedeiro de muitas das moléstias que ocorrem nas culturas do milho e da soja. Dessa forma, pode ser implantado como primeira cultura (safra) em regiões mais frias, como no sudoeste do Paraná e regiões mais altas do Rio Grande do Sul, e como cultura de safra ou safrinha em regiões mais quentes, como oeste e norte do Estado do Paraná. O elevado teor de óleo nos grãos (45 a 50\%) credencia esta cultura como uma das principais opções para produção de biodiese1, embora a utilização com essa finalidade venha sendo questionada, em razão de o seu óleo ser alimento humano de elevada qualidade (Gazzoni, 2005).

Estudos revelam que plantas de girassol podem interferir no desenvolvimento de plantas vizinhas. Gawronska et al. (2004), testando diferentes concentrações de extratos aquosos de folhas de girassol sobre a germinação e o desenvolvimento de plântulas de trigo (Triticum aestivum) e mostarda (Sinapis alba), observaram que a germinação de sementes e o crescimento radicular de mostarda foram mais inibidos que os de trigo. Extratos de folhas de dois cultivares de girassol com concentração de $10 \%$ inibiram fortemente a germinação e o desenvolvimento de plântulas de mostarda (Sinapis alba) (Bogatek et al., 2006). Diferentes concentrações de extratos aquosos de folhas de girassol reduziram a germinação de mostarda e rabanete em 41 e $69 \%$, respectivamente, na concentração mais alta, enquanto trigo e pepino apresentaram inibições de $6 \mathrm{e}$ $8 \%$, respectivamente (Ciarka et al., 2004). Os mecanismos responsáveis por esses efeitos não são bem conhecidos, porém provavelmente ocorrem porque o girassol é fonte de sesquiterpenoides e outros compostos com atividade biológica (Macías et al., 2003), variável entre genótipos de girassol (Leather, 1983).

Este trabalho objetivou avaliar o efeito alelopático da cultura do girassol sobre diferentes espécies de plantas daninhas e cultivadas e a capacidade diferencial de genótipos de girassol em suprimir a germinação e o desenvolvimento de plântulas de picão-preto (Bidens pilosa).

\section{MATERIAL E MÉTODOS}

Foram realizados dois experimentos no Laboratório de Sementes da UTFPR, campus Pato Branco, no delineamento experimental completamente casualizado. O primeiro experimento foi conduzido com quatro repetições, em esquema bifatorial, sendo o primeiro fator constituído pelas seis espécies indicadoras e o segundo pela presença ou não de plântulas de girassol. Utilizou-se o método de semeadura em substituição, adaptado de Olofsdotter et al. (1999). Quatorze sementes do cultivar BRS 122 de girassol foram colocadas em cada caixa gerbox transparente, com capacidade para $250 \mathrm{~mL}$. No fundo da caixa foram colocadas duas camadas de papel-filtro umedecido com $5 \mathrm{~mL}$ de água destilada e, acima destas camadas, depositaram-se as sementes de girassol, sendo estas cobertas com $150 \mathrm{~g}$ de resíduo de basalto, obtido a partir de material bruto, peneirado e retido entre peneiras em um intervalo entre 4,85 e 2,0 mm de diâmetro. O resíduo de basalto foi lavado sobre peneira e posteriormente deixado em uma solução de hipoclorito de $\mathrm{Na}$ comercial a $5 \%$ por duas horas. Posteriormente, o resíduo de basalto foi novamente lavado, para retirar o excesso de hipoclorito de $\mathrm{Na}$. 
As espécies indicadoras utilizadas foram: corda-de-viola (Ipomoea grandifolia), caruru (Amaranthus hybridus), alface (Lactuca sativa, cultivar Aurélia), tomate (Lycopersicon esculentum, cultivar Santa Cruz), trigo (Triticum aestivum, cultivar BRS 208) e picão-preto (Bidens pilosa). As sementes de girassol foram adquiridas nas seguintes instituições: Embrapa Soja (Londrina, PR), CEAPAR Cerrado Sementes (Rio Verde, GO) e Atlântida Sementes (Rio Verde, GO). Para evitar possiveis contaminações, as sementes foram desinfestadas em solução com $50 \%$ v/v de hipoclorito de sódio comercial por $15 \mathrm{~min}$ e, posteriormente, submetidas a três lavagens em água destilada.

As sementes de girassol foram cultivadas nas caixas gerbox por sete dias, em câmara de crescimento, a $28{ }^{\circ} \mathrm{C}$, sob fotoperiodo de $11 \mathrm{~h}$ - período após o qual foi efetuado o raleio, para uniformizar o número de plântulas em nove por caixa. Após esse período, sementes das espécies indicadoras picão-preto, corda-deviola, caruru, alface, tomate e trigo foram introduzidas nas caixas gerbox, sendo depositadas no meio da camada de basalto, para germinar em sistema de substituição, junto às plântulas de girassol, por um período de sete dias.

O segundo experimento foi composto por 24 tratamentos, representados pelos genótipos de girassol e por uma testemunha sem girassol, utilizando-se quatro repetições. Seguiuse a mesma metodologia utilizada e descrita no primeiro experimento; para este foram utilizadas apenas sementes da espécie indicadora picão-preto. Essas foram introduzidas nas caixas gerbox para germinar em sistema de substituição, junto às plântulas dos genótipos de girassol, por um período de sete dias.

A avaliação dos resultados em ambos os experimentos foi realizada no final do período de sete dias de convivio entre as espécies através da quantificação do número de sementes das espécies indicadoras germinadas, utilizando-se como critério de germinação a protrusão de pelo menos $2 \mathrm{~mm}$ da radícula. Foi avaliado, também, o comprimento radicular e da parte aérea das plântulas indicadoras, considerando-se apenas as sementes germinadas.
Os resultados foram submetidos à análise da variância pelo teste $\mathrm{F}$ e, em caso de significância, procedeu-se às comparações de médias pelo teste de Scott $\&$ Knott a $5 \%$ de significância.

\section{RESULTADOS E DISCUSSÃO}

Em relação à germinação das espéciesalvo, não houve significância para a interação espécies-alvo $\mathrm{x}$ presença ou não de plantas de girassol. Contudo, houve significância do fator principal espécie-alvo. Não houve diferenças estatísticas entre as porcentagens de germinação de quaisquer das espécies-alvo avaliadas, em função da presença ou não das plântulas de girassol cv. BRS 122 (Tabela 1).

Em geral, os percentuais de germinação das espécies daninhas foram mais baixos do que das cultivadas (Tabela 1). Esses resultados eram esperados, pela maior variabilidade genética das populações daninhas (Radosevich et al., 1997) e também porque essas espécies apresentam, de modo geral, maior dormência nas sementes mesmo quando estas são coletadas em um mesmo local. Às vezes, a variação de niveis de dormência ocorre entre sementes pertencentes à mesma planta (Toledo et al., 1993).

A presença de plântulas de girassol cv. BRS 122 não resultou em modificação nos comprimentos das raízes de picão-preto, caruru, corda-de-viola e alface, em relação à testemunha sem girassol, demonstrando a inexistência de efeito estimulativo ou inibitório ao desenvolvimento desse órgão nessas espécies (Tabela 1). O convivio com girassol estimulou o crescimento radicular das plântulas de tomate em $147 \%$ e inibiu o crescimento radicular das de trigo em $22 \%$ (Tabela 1 ).

A comparação dos tratamentos com e sem a presença de girassol demonstrou que os comprimentos das partes aéreas de caruru, corda-de-viola e tomate não foram inibidos ou estimulados pela presença de plântulas de girassol. No entanto, o girassol apresentou efeito inibitório sobre o crescimento epígeo das plântulas de picão-preto, trigo e corda-de-viola, correspondentes a, respectivamente, 42,47 e $38 \%$, em relação aos tratamentos sem a presença dessa espécie (Tabela 1). Inibição diferencial em órgãos de plantas indicadora 
Tabela 1 - Interferência de plântulas de girassol, cultivar BRS 122, sobre a germinação e o comprimento da raiz e da parte aérea (P.A.) de seis espécies indicadoras. UTFPR, campus Pato Branco, 2008

\begin{tabular}{|c|c|c|c|c|c|c|c|c|c|c|c|c|}
\hline & \multicolumn{12}{|c|}{ Espécie indicadora } \\
\hline & \multicolumn{2}{|c|}{ BIDPI } & \multicolumn{2}{|c|}{ AMACR } & \multicolumn{2}{|c|}{ IAOGR } & \multicolumn{2}{|c|}{ L. sativa } & \multicolumn{2}{|c|}{ L. esculentum } & \multicolumn{2}{|c|}{ T. aestivum } \\
\hline & Sem & Com & Sem & Com & Sem & Com & Sem & Com & Sem & Com & Sem & Com \\
\hline Germinação (\%) & $41,3 \mathrm{a}^{\mathbf{1}}$ & $25 \mathrm{a}$ & $61,3 \mathrm{a}$ & $50 \mathrm{a}$ & $36,3 a$ & $40 \mathrm{a}$ & $91,3 \mathrm{a}$ & $76,3 \mathrm{a}$ & $66,3 \mathrm{a}$ & $73,8 \mathrm{a}$ & $77,5 \mathrm{a}$ & $75 \mathrm{a}$ \\
\hline $\begin{array}{l}\text { Germinação média } \\
\text { entre espécies }\end{array}$ & \multicolumn{2}{|c|}{$33,15 \mathrm{~B}^{\frac{2 /}{}}$} & \multicolumn{2}{|c|}{$55,65 \mathrm{~B}$} & \multicolumn{2}{|c|}{$38,15 \mathrm{~B}$} & \multicolumn{2}{|c|}{$83,75 \mathrm{~A}$} & \multicolumn{2}{|c|}{$70,05 \mathrm{~A}$} & \multicolumn{2}{|c|}{$76,25 \mathrm{~A}$} \\
\hline \% Inibição/Estímulo & \multicolumn{2}{|c|}{$-39,4^{\frac{3}{}}$} & \multicolumn{2}{|c|}{$-18,4$} & \multicolumn{2}{|c|}{$+10,3$} & \multicolumn{2}{|c|}{$-16,4$} & \multicolumn{2}{|c|}{$+11,3$} & \multicolumn{2}{|c|}{$-3,2$} \\
\hline $\begin{array}{l}\text { Comprimento } \\
\text { Radicular }\end{array}$ & $1,46 \mathrm{a}^{4 /} \mathrm{B}$ & $2,00 \mathrm{aB}$ & $0,76 \mathrm{aC}$ & $0,82 \mathrm{aC}$ & $1,96 \mathrm{aB}$ & $2,34 \mathrm{aB}$ & $1,47 \mathrm{aB}$ & $1,93 \mathrm{aB}$ & $0,97 \mathrm{bC}$ & $2,42 \mathrm{aB}$ & $9,24 \mathrm{aA}$ & $7,22 \mathrm{bA}$ \\
\hline \% Inibição/Estímulo & \multicolumn{2}{|c|}{$+37,7^{3}$} & \multicolumn{2}{|c|}{$-6,5$} & \multicolumn{2}{|c|}{$+19,4$} & \multicolumn{2}{|c|}{$+31,3$} & \multicolumn{2}{|c|}{$+146,9$} & \multicolumn{2}{|c|}{$-21,9$} \\
\hline $\begin{array}{l}\text { Comprimento de } \\
\text { P.A. }\end{array}$ & $3,96 \mathrm{a}^{\mathbf{4} /} \mathrm{C}$ & $2,28 \mathrm{bC}$ & $0,99 \mathrm{aD}$ & $1,28 \mathrm{aC}$ & $6,45 \mathrm{aB}$ & $4,64 \mathrm{bB}$ & $3,45 \mathrm{aC}$ & $2,14 \mathrm{aC}$ & $2,68 \mathrm{aC}$ & $2,93 \mathrm{aC}$ & 13,41 aA & $7,08 \mathrm{bA}$ \\
\hline \% Inibição/Estímulo & \multicolumn{2}{|c|}{$-42,4^{3}$} & \multicolumn{2}{|c|}{$+30,3$} & \multicolumn{2}{|c|}{$-28,7$} & \multicolumn{2}{|c|}{$-38,1$} & \multicolumn{2}{|c|}{$+9,7$} & \multicolumn{2}{|c|}{$-47,2$} \\
\hline
\end{tabular}

1/ Médias com mesma letra minúscula na linha indicam ausência de diferenças significativas entre tratamento sem e com girassol pelo teste de Scott Knott a 5\% de significância. ${ }^{2 /}$ Médias com mesma letra maiúscula na linha indicam ausência de diferenças significativas entre as espécies pelo teste de Scott Knott a 5\% de significância. 르 Calculada em relação à testemunha sem girassol. Sinal positivo significa promoção e sinal negativo inibição da germinação da espécie-alvo pelo girassol. " ${ }^{4 /}$ Médias com mesma letra minúscula na linha indicam ausência de diferenças significativas entre tratamento sem e com girassol, dentro de cada espécie; médias com mesma letra maiúscula na linha indicam ausência de diferença entre espécies, dentro de, sem e com girassol, pelo teste de Scott Knott a 5\% de significância.

$\mathrm{BIDPI}=$ Bidens pilosa; $\mathrm{AMACR}=$ Amaranthus hybridus; $\mathrm{IAOGR}=$ Ipomoea grandifolia .

Coeficientes de variação (\%): Germinação $=24,2$; Comprimento da raiz $=20,3$; Comprimento de parte aérea $=23,4$.

também foi demonstrada por Prates et al. (2000), em que extratos de leucena (Leucena leucocephala) não inibiram a germinação e o surgimento de raízes secundárias de milho, porém afetaram o comprimento e a biomassa seca da parte aérea, das raízes e total das plântulas de milho.

Variabilidade entre espécies indicadoras quanto ao efeito de extratos aquosos de girassol foi constatada por Ciarka et al. (2004). Neste experimento, foram avaliadas concentrações de extratos de folha e colmo sobre a germinação de trigo (Triticum aestivum), centeio (Secale cereale), cevada (Hordeum sativum), aveia (Avena sativa), mostarda (Sinapis alba), pepino (Cucumis sativus), tomate (Lycopersicon aesculenthum), alface (Lactuca sativa) e rabanete (Raphanus sativa) e constatou-se que cereais e pepino foram menos afetados pelos extratos aquosos de girassol que alface, tomate e mostarda.

Na seleção de espécie indicadora para testes de alelopatia é comum deparar-se com características favoráveis e desfavoráveis das espécies. Em teoria, a espécie mais adequada seria aquela objeto dos compostos alelopáticos no meio ambiente, de forma que se aproximasse da situação real de campo. No entanto, fatores como a presença de dormência ou de variabilidade genética intrínseca, apresentados frequentemente em espécies daninhas, podem dificultar a obtenção de resultados precisos. Características importantes, como alta taxa de crescimento e homogeneidade genética, encontradas normalmente em espécies cultivadas, são importantes na definição de espécies indicadoras. A alta taxa de crescimento permite rápida visualização dos sintomas ocorridos, e a homogeneidade genética padroniza as respostas obtidas e possibilita maior homoscedasticidade da variância na análise dos dados em estudos realizados por meio de bioensaios, em que o comportamento da planta é utilizado como indicador de um certo efeito (Nunes, 2007). No presente experimento, isso pode ter contribuído para que, principalmente nas espécies cultivadas, tenha havido diferenças entre os tratamentos com e sem a presença de girassol quanto às variáveis analisadas (Tabela 1 ).

A variabilidade de resposta sobre as espécies indicadoras pode ser atribuída à sensibilidade diferencial das espécies, assim como à técnica utilizada para avaliar alelopatia. Os experimentos conduzidos pela técnica de semeadura de substituição apresentam a vantagem de simular a interferência entre plantas em estádios iniciais de desenvolvimento, momento em que o processo alelopático 
poderá ser determinante para o estabelecimento das plântulas, enquanto os ensaios com extratos são mais utilizados para determinar a liberação de compostos alelopáticos em momentos posteriores, em que as plantas doadoras estão mais desenvolvidas ou mesmo em processo de decomposição. Uma crítica que se pode fazer a ambas as metodologias é que por meio delas não se conhecem as concentrações das substâncias liberadas no meio. No entanto, a técnica da semeadura em substituição simula com maior aproximação a situação das plantas em campo.

Plantas liberam no ambiente diversos compostos do metabolismo secundário (Einhellig, 1996). Os efeitos observados pela utilização da semeadura em substituição, resultantes do convivio entre plântulas, provavelmente são devidos à liberação de compostos alelopáticos - alguns com maior e outros com menor atividade sobre espécies indicadoras. Compostos isolados de girassol foram capazes de inibir em $50 \%$ a germinação de alface e em $47 \%$ a de cebola, porém estimularam em até $63 \%$ o comprimento do sistema radicular de cebola, em $47 \%$ o de alface e em $30 \%$ o crescimento de parte aérea de cevada (Macías et al., 1998).

Para que substâncias alelopáticas exerçam ação sobre as plantas indicadora, diferentes etapas devem ser cumpridas. Os compostos devem ser liberados das plantas doadoras em taxas adequadas, apresentar-se em concentrações suficientes, ser absorvidos e translocados e agir sobre algum mecanismo bioquímico relevante, para resultar em inibição comprometedora à planta. $\mathrm{O}$ fato de os mecanismos de absorção, translocação, metabolização e de o local de ação variarem entre as espécies receptoras explica as diferenças de seletividade entre as espécies testadas no presente experimento. Essas diferenças, aliadas às diferenças anatômico-fisiológicas dos tecidos das plantas, podem explicar a existência de respostas diferenciadas entre o sistema radicular e a parte aérea de algumas espécies testadas.

Os genótipos de girassol influenciaram distintamente as respostas de germinação, comprimento radicular e da parte aérea de plantas de picão-preto (Tabela 2). Os genótipos V 80198 e MG 50 proporcionaram os maiores indices de germinação de picão-preto (80\%) esse valor foi $60 \%$ maior que a média da germinação da testemunha sem girassol (Tabela 2). No entanto, os efeitos desses genótipos sobre a germinação da espécie indicadora não diferiram dos de AG 930, Hélio 358, BRS 122, Hélio 251, Multissol, AG 962 e AG 972. A comparação estatística da germinação de sementes de picão-preto na presença dos genótipos de girassol com a testemunha sem a presença de girassol demonstra que nenhum genótipo inibiu a germinação. $O$ genótipo Aguará 04 apresentou, numericamente, a maior inibição percentual das sementes de picão-preto $(10 \%)$, quando comparado à testemunha (Tabela 2), mas não diferiu significativamente de HLE 05, HLE 04, V 30005, Nutrisso1, AG 967, HLA AC 4861, ACA 864 DM, HLE 03, HLE 07, BRHS 05, Hélio 252, Paraíso 20, Hélio 360 e da testemunha. Foi observada grande variabilidade entre os genótipos testados quanto à inibição ou estimulação do desenvolvimento de picãopreto. Os efeitos estimulativos à germinação foram mais comuns do que os inibitórios.

Apenas um dos 23 genótipos de girassol testados foi estimulativo ao crescimento radicular de picão-preto, enquanto todos os demais foram inibitórios (Tabela 2). Os mecanismos responsáveis por esses efeitos inibitórios não são bem conhecidos, porém, provavelmente, ocorrem porque o girassol é fonte de lactonas sesquiterpênicas e outros compostos com atividade biológica (Macias et al., 2003). Acredita-se que a maioria desses compostos exerce sua atividade através de um mecanismo químico de ação comum, que é a alquilação de moléculas orgânicas. Um grande número de enzimas e outras macromoléculas essenciais são inibidas por lactonas sesquiterpênicas, usualmente em baixas concentrações (Schimidt, 1999).

Sesquiterpenos provenientes de Artemisia annua provocaram inibição do crescimento radicular de sementes de alface e azevém (Dayan et al., 1999). O sesquiterpeno artemisinina reduziu a mitose em células do meristema apical de raízes de cebola e afetou diretamente a divisão celular das sementes indicadoras de alface e azevém. Foi observada a produção de fases mitóticas aberrantes, em que os cromossomos, apesar de bem definidos, 
Tabela 2 - Germinação, comprimento de raiz e da parte aérea (P.A.) de Bidens pilosa e correspondentes percentuais de inibição/ estimulação por diferentes genótipos de H. annuus. UTFPR, campus Pato Branco, 2008

\begin{tabular}{|c|c|c|c|c|c|c|}
\hline Cultivar & Germinação (\%) & $\begin{array}{c}\text { Inibição/Estímulo } \\
\text { da germinação } \\
(\%)^{2 /}\end{array}$ & $\begin{array}{l}\text { Comprimento da } \\
\text { raiz }(\mathrm{cm})\end{array}$ & $\begin{array}{c}\text { Inibição/Estímulo } \\
\text { do comprimento } \\
\text { da raiz }(\%)^{2 /}\end{array}$ & $\begin{array}{l}\text { Comprimento da } \\
\text { parte aérea }(\mathrm{cm})\end{array}$ & $\begin{array}{c}\text { Inibição/Estímulo } \\
\text { do comprimento } \\
\text { da P.A. }(\%)^{\underline{2} /}\end{array}$ \\
\hline AG 930 & $66 \mathrm{a}^{\frac{1}{1 /}}$ & 32 & $2,5 \mathrm{c}^{\mathrm{1}^{\prime}}$ & $-25,7$ & $3,03 \mathrm{c}^{1^{\prime}}$ & $-6,27$ \\
\hline Hélio 358 & $73 \mathrm{a}$ & 46 & $1,9 \mathrm{~d}$ & $-44,8$ & $3,65 \mathrm{~b}$ & 12,85 \\
\hline Aguará 04 & $45 \mathrm{~b}$ & -10 & $1,8 \mathrm{~d}$ & -46 & $2,79 \mathrm{~d}$ & $-13,70$ \\
\hline HLE 05 & $61 \mathrm{~b}$ & 22 & $1,7 \mathrm{~d}$ & $-51,2$ & $2,71 \mathrm{~d}$ & $-16,18$ \\
\hline HLE 04 & $54 \mathrm{~b}$ & 8 & $2,4 \mathrm{c}$ & $-29,7$ & $2,88 \mathrm{~d}$ & $-10,91$ \\
\hline V 80198 & $80 \mathrm{a}$ & 60 & $1,9 \mathrm{~d}$ & $-45,1$ & $3,86 \mathrm{~b}$ & 19,58 \\
\hline BRS 122 & $72 \mathrm{a}$ & 44 & $2,3 \mathrm{c}$ & $-32,7$ & $3,20 \mathrm{c}$ & $-0,85$ \\
\hline $\begin{array}{l}\text { V } 30005 \\
\end{array}$ & $59 \mathrm{~b}$ & 18 & $2,5 \mathrm{c}$ & $-25,3$ & $2,33 \mathrm{~d}$ & $-27,86$ \\
\hline Nutrissol & $63 \mathrm{~b}$ & 26 & $2,3 \mathrm{c}$ & $-33,4$ & $2,82 \mathrm{~d}$ & $-12,77$ \\
\hline AG 967 & $60 \mathrm{~b}$ & 20 & $2,9 \mathrm{c}$ & $-15,3$ & $3,11 \mathrm{c}$ & $-3,64$ \\
\hline Hélio 251 & $68 \mathrm{a}$ & 36 & $2,1 \mathrm{~d}$ & $-37,3$ & $4,18 \mathrm{a}$ & 29,41 \\
\hline MG 50 & $80 a$ & 60 & $2,1 \mathrm{~d}$ & $-37,1$ & $3,15 \mathrm{c}$ & $-2,48$ \\
\hline HLA AC 4861 & $50 \mathrm{~b}$ & 0 & $1,8 \mathrm{~d}$ & $-46,2$ & $3,60 \mathrm{~b}$ & 11,46 \\
\hline ACA 864 DM & $60 \mathrm{~b}$ & 20 & $2,4 \mathrm{c}$ & $-28,5$ & $3,61 \mathrm{~b}$ & 11,69 \\
\hline Multissol & $68 \mathrm{a}$ & 36 & $1,7 \mathrm{~d}$ & $-49,3$ & $4,48 \mathrm{a}$ & 38,54 \\
\hline AG 962 & $69 \mathrm{a}$ & 38 & $1,9 \mathrm{~d}$ & $-42,6$ & $4,45 \mathrm{a}$ & 37,93 \\
\hline HLE 03 & $55 \mathrm{~b}$ & 10 & $2,9 \mathrm{c}$ & $-14,3$ & $2,42 \mathrm{~d}$ & $-25,23$ \\
\hline HLE 07 & $46 \mathrm{~b}$ & -8 & $2,6 \mathrm{c}$ & -23 & $2,67 \mathrm{~d}$ & $-17,34$ \\
\hline AG 972 & $72 \mathrm{a}$ & 44 & $4,7 \mathrm{a}$ & 38,9 & $2,82 \mathrm{~d}$ & $-12,69$ \\
\hline BRHS 05 & $60 \mathrm{~b}$ & 20 & $2,1 \mathrm{~d}$ & $-39,2$ & $3,76 \mathrm{~b}$ & 16,49 \\
\hline Hélio 252 & $56 \mathrm{~b}$ & 12 & $2,3 \mathrm{c}$ & $-31,7$ & $3,75 \mathrm{~b}$ & 15,94 \\
\hline Paraíso 20 & $54 \mathrm{~b}$ & 8 & $2,5 \mathrm{c}$ & $-27,5$ & $3,08 \mathrm{c}$ & $-4,57$ \\
\hline Hélio 360 & $62 \mathrm{~b}$ & 24 & $2,3 \mathrm{c}$ & $-31,4$ & $2,90 \mathrm{~d}$ & $-10,37$ \\
\hline Testemunha & $50 \mathrm{~b}$ & 0 & $3,4 \mathrm{~b}$ & 0,00 & $3,23 \mathrm{c}$ & 0,00 \\
\hline
\end{tabular}

1/ Médias seguidas de mesma letra minúscula na coluna não diferem entre si pelo teste de Scott \& Knott a 5\%. 르 Calculada em relação ao percentual de germinação da testemunha. Sinal positivo significa promoção e sinal negativo inibição da germinação pelo girassol.

não estavam corretamente arranjados dentro das células.

Para a variável comprimento radicular, observou-se que AG 972 proporcionou aumento de $4,7 \mathrm{~cm}$, superando em $38,9 \%$ a testemunha sem girassol; já o genótipo HLE 05 foi o que mais evoluiu, apresentando desenvolvimento radicular médio de 1,66 cm e inibição de 51,2\% em relação à testemunha (Tabela 2).

Com relação ao comprimento de parte aérea, observou-se que o genótipo de girassol Multissol foi o mais estimulativo (comprimento médio de 4,48 cm), no entanto não diferiu significativamente dos genótipos AG 962 e Hélio 251 (comprimentos médios de 4,46 e $4,18 \mathrm{~cm}$, respectivamente) (Tabela 2). O genótipo V30005 resultou no menor comprimento da parte aérea (média de 2,33 cm), com inibição percentual do crescimento epígeo de $27,2 \%$, em relação à testemunha (Tabela 2).
Os resultados demonstram que a técnica da semeadura em substituição é adequada para discriminar genótipos de girassol quanto à habilidade em inibir ou estimular plântulas de Bidens pilosa. Os resultados encontrados demonstram haver grande variabilidade de potencial alelopático entre genótipos de girassol sobre o desenvolvimento de Bidens pilosa.

A habilidade de genótipos de espécies cultivadas em produzir efeitos inibitórios distintos entre si é conhecida há bastante tempo. A análise de 526 genótipos de pepino indicou que um genótipo inibiu em $87 \%$ o desenvolvimento de Panicum milliaceum, enquanto outros 25 inibiram em $50 \%$ o desenvolvimento daquela espécie (Putnam \& Duke, 1974). Jacobi \& Fleck (2000) avaliaram 20 genótipos de aveia e observaram que quatro materiais produziram valores mais altos de escopoletina, sendo considerados mais alelopáticos e proporcionando maior fitotoxidade sobre azevém (Lolium multiflorum). 
Os resultados encontrados nestes experimentos indicam que a técnica de semeadura em substituição utilizando plântulas de girassol como espécie doadora é adequada para detectar efeitos estimulativos ou inibitórios. Esses efeitos dependem da espécie indicadora considerada. Maiores efeitos inibitórios de girassol foram verificados sobre o crescimento da radícula e parte aérea do trigo, e o maior efeito estimulativo foi encontrado sobre o crescimento do sistema radicular do tomate. Das espécies indicadoras avaliadas, a única em que as plântulas de girassol inibiram tanto o sistema radicular quanto a parte aérea foi o trigo. Entre as espécies daninhas, apenas o picão-preto e a corda-de-viola tiveram seu crescimento modificado (inibido) pela presença de girassol e, portanto, podem ser utilizados como espécie daninha indicadora em ensaios que adotem a técnica da semeadura de substituição, para avaliar o potencial alelopático de girassol.

A variabilidade de inibição ou estimulação existente entre genótipos de girassol poderá ser utilizada em programas de melhoramento genético, pois os genótipos mais inibitórios poderão ser utilizados em cruzamentos, com o intuito de obter aqueles com maior habilidade alelopática sobre plantas daninhas. No entanto, é interessante, primeiramente, que novas pesquisas sejam desenvolvidas, para avaliar se os genótipos que apresentaram maior habilidade alelopática em laboratório também apresentam essas características em condições de campo.

\section{AGRADECIMENTOS}

À UTFPR, pelos recursos financeiros que permitiram a execução do trabalho.

À pesquisadora da Embrapa Soja Regina Villas Bôas Campos Leite e às empresas CEAPAR Cerrado Sementes e Atlântida Sementes, pela doação das sementes de girassol.

\section{LITERATURA CITADA}

BOGATEK, R. et al. Allelopathic effects of sunflower extracts on mustard seed germination and seedling growth. Biol. Plant., v. 50, n. 1, p. 156-158, 2006.

CASTRO, C.; FARIAS, J. R. B. Ecofisiologia do girassol. In: LEITE, M. R. V.; BRIGHENTI, A. M.; CASTRO, C. Girassol no Brasil. Londrina: Embrapa Soja, 2005. p. 163-218.
CIARKA, D. et al. Crops species reaction to sunflower allelopathics. In: EUROPEAN ALLELOPATHY SYMPOSIUM "ALLELOPATHY - FROM UNDERSTANDING TO APPLICATION, 2., Pulawy, Poland, 2004. Proceedings... Pulawy: 2004. p. 123.

Disponível em: <http://seas.iung.pulawy.pl/pdf/str123.pdf>. Acesso em: 8 out. 2008

DAYAN, F. E. et al. Comparative phytotoxicity of artemisinin and several sesquiterpene analogues. Phytochemistry, v. 50, n. 4, p. 607-614, 1999.

EINHELLIG, F. A. Interactions involving allelopathy in cropping systems. Agron. J., v. 88, n. 6., p. 886-893, 1996.

ERASMO, E. A. L. et al. Potencial de espécies utilizadas como adubo verde no manejo integrado de plantas daninhas. Planta Daninha, v. 22, n. 3, p. 337-342, 2004.

FERREIRA, A. G.; ÁQUILA, M. E. A. Alelopatia: uma área emergente da ecofisiologia. R. Bras. Fisiol. Veg., v. 12, p. 175-204, 2000. Edição Especial.

GAWRONSKA, H. et al. Comparative studies on wheat and mustard responses to allelochemicals of sunflower origin. In: EUROPEAN ALLELOPATHY SYMPOSIUM

"ALLELOPATHY - FROM UNDERSTANDING TO APPLICATION, 2., Pulawy, Poland, 3-5 June 2004. Proceedings... Pulawy: 2004. p. 28. Disponível em: <http:// seas.iung.pulawy.pl/pdf/str123.pdf $>$. Acesso em: 10 out. 2008

GAZZONI, D. L. Óleo de girassol como matéria-prima para biocombustíveis. In: LEITE, R. V. B. C.; BRIGHENTI, A. M.; CASTRO, C. Girassol no Brasil. Londrina: Embrapa Soja, 2005.

JACOBI, U. S.; FLECK, N. G. Avaliação do potencial alelopático de genótipos de aveia no início do ciclo. Pesq. Agropec. Bras., v. 35, v. 1, p. 11-19, 2000

LEATHER, G. R. Sunflowers (Helianthus annuus) are allelopathic to weeds. Weed Sci., v. 31, n. 1, p. 37-42, 1983

MACÍAS, F. A. et al. Bioactive norsesquiterpenes from Helianthus annuus with potential allelopathic activity. Phytochemistry, v. 48, n. 4, p. 631-636, 1998.

MACÍAS, F. A. et al. Allelopathy as a new strategy for sustainable ecosystems development. Biol. Sci. Space, v. 17, n. 1, p. 18-23, 2003

NUNES, A. L. Persistência e lixiviação dos herbicidas residuais $\mathrm{S}$-metolochlor e imazaquin associados ao paraquat ou glyphosate. 2007. 120 f. Dissertação (Mestrado em Fitotecnia) - Universidade Federal do Rio Grande do Sul, Porto Alegre, 2007.

OLOFSDOTTER, M. et al. Weed suppressing rice cultivars does allelopathy play a role? Weed Res., v. 39, n. 6 , p. $441-454,1999$. 
PERES, M. T. L. P. et al. Potencial alelopático de espécies de Pteridaceae (Pteridophyta). Acta Bot. Bras., v. 18, n. 4 , p. 723-730, 2004.

PRATES, H. T. et al. Efeito do extrato aquoso de leucena na germinação e no desenvolvimento do milho. Pesq. Agropec. Bras., v. 35, n. 5, p. 909-914, 2000.

PUTNAM, A. R.; DUKE, W. B. Biological suppression of weeds: evidence for allelopathy in accessions of cucumber. Science, v. 1985, n 3, p. 370-372, 1974.
RADOSEVICH, S. et al. Weed ecology: implications for management. 2.ed. New York: John Willey \& Sons, 1997. $588 \mathrm{p}$.

SCHIMIDT, T. J. Toxic activities of sesquiterpene lactones structural and biochemical aspects. Current Org. Chem. v. 3, n. 3, p. 577-608, 1999.

TOLEDO, R. E. B. et al. Fatores que afetam a germinação e a emergência de Xanthium strumarim 1.: dormência, qualidade da luz e profundidade de semeadura. Planta Daninha, v. 11, n. 1, p. $15-20,1993$ 